MATEC Web of Conferences 25, 02001

(2015)

DOI: $10.1051 /$ matec conf/ 20152502001

(c) Owned by the authors, published by EDP Sciences, 2015

\title{
An Influence Study of Hydrogen Evolution Characteristics on the Negative Strap Corrosion of Lead Acid Battery
}

\author{
Guobin Zhong \& Wei Su \\ Electric Power Research Institute, Guangdong Power Grid Co., LTD, Guangzhou, Guangdong, China
}

Dong Chen*, Jiayuan Xiang, Xianzhang Wu \& Jian Chen

Narada Power Source Co., LTD, Hangzhou, Zhejiang, China

\begin{abstract}
Negative strap corrosion is an important reason for the failure of valve regulated lead acid battery. This paper selected the $\mathrm{Pb}-\mathrm{Sb}$ alloy material and $\mathrm{Pb}-\mathrm{Sn}$ alloy material, made an investigation on the negative corrosion resistance and hydrogen evolution of these two alloy materials by scanning electron microscope analysis, metallographic analysis, chemical study and linear sweep voltammetry, and discussed the influence of lead alloy hydrogen evolution on the negative strap corrosion. The results showed that the hydrogen evolution reaction rates of the alloys had an impact on the corrosion areas with the maximum thickness of the alloys and the depth of corrosion layers. Greater hydrogen evolution reaction rate can lead to shorter distance between the corrosion area with the maximum thickness and the liquid level; whereas the greater corrosion layer thickness can bring aggravated risk of negative strap corrosion failure.
\end{abstract}

Keywords: valve regulated lead acid batteries; negative bus-bar; lead alloy; corrosion; hydrogen evolution reaction rate

\section{INTRODUCTION}

The Valve Regulated Lead Acid (VRLA) battery has become an essential aspect of lead acid battery due to its advantages, such as maintenance free, no excessive acid, no acid mist, high-rate discharge performance, and convenience in storage. As alloy corrosion is one of the main reasons affecting the validity of VRLA battery, people have made a great deal of research work on the corrosion of positive grid alloy ${ }^{[1-3]}$ Comparatively speaking, there are few reports about negative corrosion study. In the actual application of battery, the negative strap corrosion is a main reason for the VRLA battery failure ${ }^{[4,5]}$

As a result of electrochemical corrosion and chemical corrosion, negative strap corrosion is a complex process Researches about negative strap corrosion have been published in various documents ${ }^{[6-8]}$, and researchers hold different opinions about the cause of negative bus-bar corrosion. For example, Pavlov D et al. ${ }^{[6]}$ think oxygen absorption corrosion is brought by the lost cathodic protection of alloy resulting from the increased electric potential on negative strap surface caused by the oxygenation reaction depolarization. However, Hua S et al. ${ }^{[7]}$ regard the corrosion between negative strap alloys as a result of differences in negative strap alloy metallographic structures. Omae $\mathrm{T}$ et al. ${ }^{[8]}$ hold the view that negative strap hydrogen evolution corrosion is caused by the local cell reaction resulting from the hydrogen evolution reaction and $\mathrm{Pb}$ dissolution reaction of alloy near $\mathrm{Pb} / \mathrm{PbSO}_{4}$ equilibrium potential.

This paper selected $\mathrm{Pb}-\mathrm{Sb}$ alloy material and $\mathrm{Pb}-\mathrm{Sn}$ *Corresponding author: chendong0127@,126.com alloy material as the negative strap alloy materials, made an investigation on the negative corrosion resistance and corrosion mechanism of these two alloy materials by scanning electron microscope analysis, metallographic analysis, chemical study, and linear scanning voltammetry, and discussed the influence of lead alloy hydrogen evolution on the negative strap corrosion, so as to further understand the negative strap corrosion mechanism of the VRLA battery.

\section{EXPERIMENTAL MATERIALS AND METH- ODS}

$\mathrm{Pb}-2$ wt. \%Sb lead alloy and $\mathrm{Pb}-2$ wt. \%Sn lead alloy were selected to make $1 \mathrm{~cm} \times 0.3 \mathrm{~cm} \times 6 \mathrm{~cm}$ alloy samples by machining. In order to simulate the bus-bar corrosion situation inside battery, the equipment ${ }^{[8]}$ applied in the experiment is shown in Figure 1 . The $\mathrm{Pb}-\mathrm{Sb}$ lead alloy sample and $\mathrm{Pb}-\mathrm{Sn}$ lead alloy sample were inserted into Absorptive Glass Mat (AGM) with $5 \mathrm{~mol} / \mathrm{L} \mathrm{H}_{2} \mathrm{SO}_{4}+0.1 \mathrm{~mol} / \mathrm{L} \mathrm{Na}_{2} \mathrm{SO}_{4}$ Solution for $1 \mathrm{~cm}$ and length of $5 \mathrm{~cm}$ was exposed in the air. The alloy samples were used as the working electrodes while the metallic lead was used as the auxiliary electrode. $\mathrm{Hg} / \mathrm{Hg}_{2} \mathrm{SO}_{4}$ electrode was applied as the reference electrode. Conduct the polarization experiment at $25^{\circ} \mathrm{C}$ and $60^{\circ} \mathrm{C}$ with constant voltage of $-1.1 \mathrm{~V}$ for 240 hours. After 240 hours of polarization under constant voltage, corrosion layers appeared on the surfaces of the alloy electrodes. All the electrochemical experiments were completed on the ARBIN BT-2000-type electrochemical workstation.

This is an Open Access article distributed under the terms of the Creative Commons Attribution License 4.0, which permits unrestricted use, distribution, and reproduction in any medium, provided the original work is properly cited. 


\section{MATEC Web of Conferences}

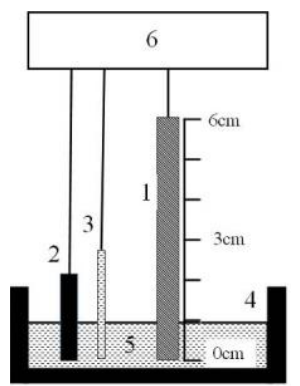

Figure 1. Setting drawing of corrosion simulation experiment

Note: 1 . alloy electrode; 2 . auxiliary electrode; 3 . reference electrode; 4. reaction vessel; 5. AGM membrane; 6 . electrochemical workstation

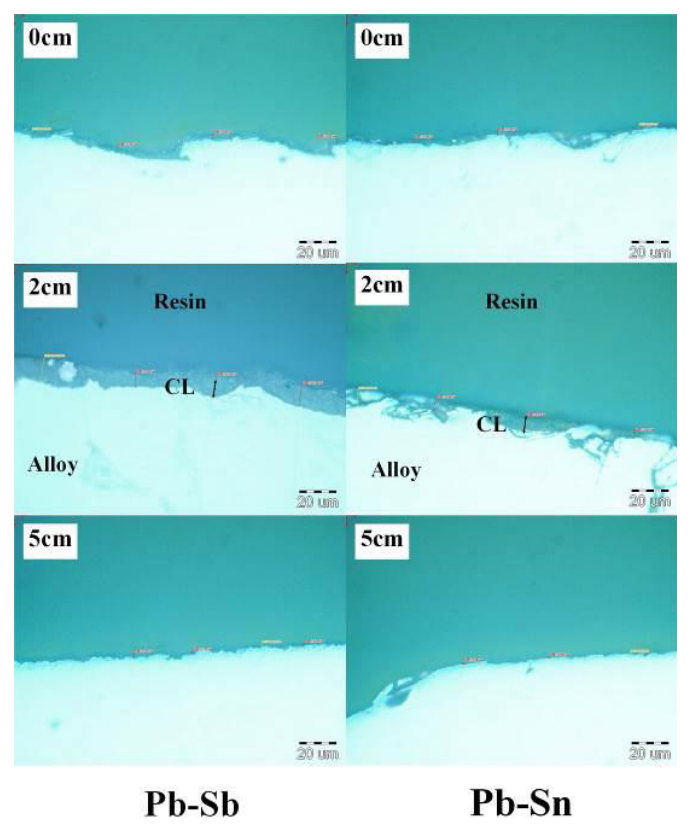

Figure 2. Cross-section metallographic microscope images of alloy at different heights $\left(25^{\circ} \mathrm{C}\right)$

After the corrosion process was completed, put the lead alloy electrodes to be soaked in deionized water for 20mins to remove the acid liquor on the surface and to be dried in oven at a temperature of $65^{\circ} \mathrm{C}$.After that, cut the corrosive lead alloy samples into 6 pieces with the same height (the ends with AGM were marked as $0 \mathrm{~cm}$ ). Hitachi S-3400N-Type electronic scanning microscope was used to observe the microstructures of the corrosion layers on the outside surfaces of the lead alloys. Olympus GX51-Type metallographic microscope was used to observe the cross sections of the alloy samples, measure the corrosion layer thickness and inspect the corrosion situation of the alloys.
The $\mathrm{Pb}$-Sb lead alloy and $\mathrm{Pb}$-Sn lead alloy were fixed in epoxy resin to make the working electrodes with an area of $1 \mathrm{~cm} \times 0.5 \mathrm{~cm}$. The sandpapers of different grits were polished to have smooth surfaces. In the experiment, the 3-electrode method was applied to test the linear scanning voltage-current curves at the temperatures of $25^{\circ} \mathrm{C}$ and $60^{\circ} \mathrm{C}$. The alloy samples were used as the working electrodes, whereas the metallic lead was used as the auxiliary electrode. $\mathrm{Hg} / \mathrm{Hg}_{2} \mathrm{SO}_{4}$ with concentration of $5 \mathrm{~mol} / \mathrm{L}$ and $\mathrm{Na}_{2} \mathrm{SO}_{4}$ with concentration of $5 \mathrm{~mol} / \mathrm{L}$ were applied as the electrolyte solution. The scanned range was $-0.8 \mathrm{~V}-$ $-1.6 \mathrm{~V}$ with a scanning rate of $10 \mathrm{mV} / \mathrm{s}$.

\section{RESULTS AND DISCUSSION}

\subsection{Corrosion property of the alloy electrode}

Cut the corrosive alloy electrodes into 6 equal pieces (the ends with AGM were marked as $0 \mathrm{~cm}$ ). Conduct metallography tests to the cross sections with different heights of alloy. See Figure 2 for the cross-section metallographic microscope images of alloy at different heights $\left(25^{\circ} \mathrm{C}\right)$. The light color shows the alloy matrix, whereas the blue color shows the coated resin. The interlayer in the dark color is corrosion layer (CL). The thickness of the corrosion layer was calculated by the averaging in multiple metering. The changing curves of alloy corrosion layer thickness $\left(25^{\circ} \mathrm{C}\right)$ were calculated according to the statistic data from the metallographic images as shown in Figure 3. It can be seen from the changes of the corrosion layer thicknesses of the alloy cross sections with different heights that with the increase of alloy electrode height, the corrosion layer thickness firstly increased and then decreased. As shown in Figure 2, both the immersed AGM part $(0 \mathrm{~cm})$ and the part far away from the liquid level $(5 \mathrm{~cm})$ were small in corrosion layer thickness. However, the corrosion in the middle of the alloy samples $(2 \mathrm{~cm})$ was in the most serious situation. In comparison, the maximum corrosion layer thicknesses of the two alloy samples both appeared at $2 \mathrm{~cm}$. The corrosion area with the maximum thickness of $\mathrm{Pb}-\mathrm{Sb}$ alloy appeared at $1-2 \mathrm{~cm}$, whereas that of $\mathrm{Pb}-\mathrm{Sn}$ alloy appeared at $2-3 \mathrm{~cm}$.

Scanning electron microscope was used to further observe the microstructures of the corrosion layer surfaces corresponding to alloy electrode height. See Figure 4 for the surface scanning electron microscope images of alloy at different heights $\left(25^{\circ} \mathrm{C}\right)$. The corrosion layers of $\mathrm{Pb}-\mathrm{Sb}$ alloy and $\mathrm{Pb}-\mathrm{Sn}$ alloy had small particles with compact layout at $0 \mathrm{~cm}$. The electrodes at this spot were in cathodic protection ${ }^{[8]}$. As the solution could provide enough $\mathrm{H}^{+}$ions for oxygen reduction, the corrosion was slight and the corrosion layers were thin. With the increase of the distance between the alloy samples and the liquid level, the surface potential of alloy increased to reach or exceed $\mathrm{Pb} / \mathrm{PbSO}_{4}$ equilibrium potential $(-0.92 \mathrm{~V}$, v.s. $\mathrm{Hg} / \mathrm{Hg}_{2} \mathrm{SO}_{4}$ ). Resulting forms the diffusion effect, the concentration of $\mathrm{H}^{+}$ions in the liquid membranes 
decreased accordingly, and thus accelerated the alloy corrosion. At $2 \mathrm{~cm}$, the particles on the corrosion layer surfaces of the alloy samples increased and formed loose porous structures. With a certain height away from the AGM membrane, corrosion layers with smooth and continuous surfaces, compact structures and no obvious corrosion appeared on the alloy samples at $5 \mathrm{~cm}$. It occurred because $\mathrm{H}^{+}$and $\mathrm{SO}_{4}{ }^{2-}$ ions could not reach the areas, and the alloy samples only had reaction with oxygen on the surface. As a result, the fine particles formed compact layers and hindered further corrosion. From the comparison of these two alloy samples, it can be seen that the corrosion layer surfaces share similar microstructures, morphologies and change laws.

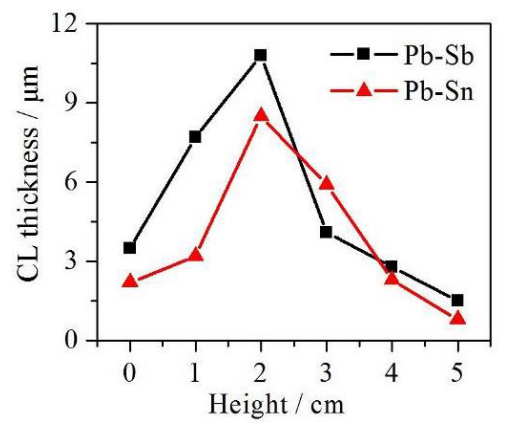

Figure 3. Changing curves of alloy corrosion layer thickness $\left(25^{\circ} \mathrm{C}\right)$

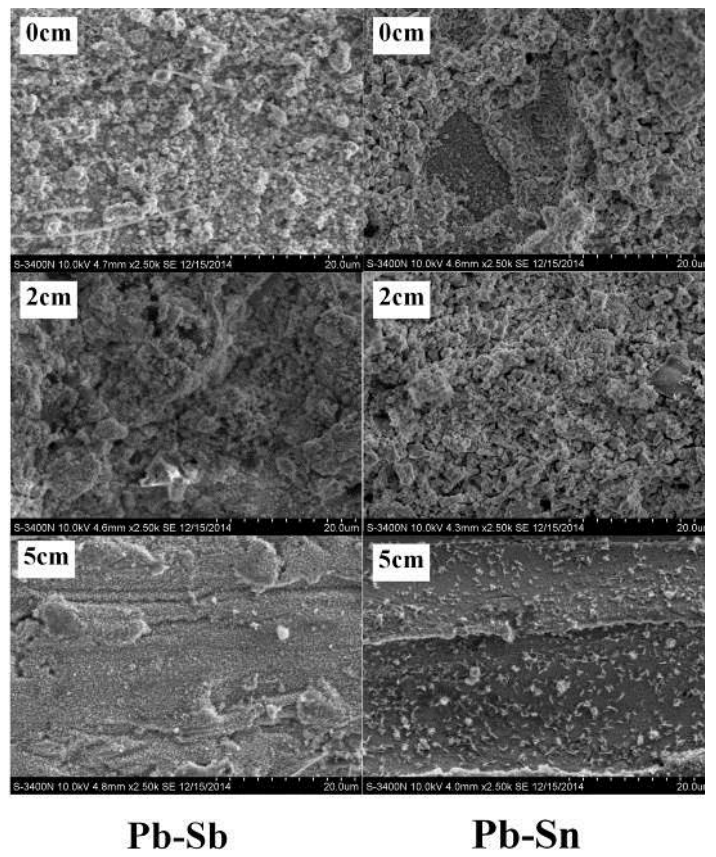

Figure 4. Surface scanning electron microscope images of alloy at different heights $\left(25^{\circ} \mathrm{C}\right)$
At normal temperature, the rate of alloy corrosion is slow. When temperature is above $60^{\circ} \mathrm{C}$, alloy corrosion will greatly accelerate. Therefore, accelerated corrosion experiment was conducted at temperature of $60^{\circ} \mathrm{C}$ to these two kinds of alloy in this paper. See Figure 5 and Figure 6 for the cross-section metallographic microscope images of alloy at different heights after accelerated corrosion processing and the changing curves of alloy corrosion layer thickness calculated herein. From Figure 6, it can be seen that with the increase of alloy electrode height, the corrosion layer thickness which is first increased and then decreased is similar to the result at temperature $25^{\circ} \mathrm{C}$. However, when the corrosion layer thickness reached its maximum value at the spot, the offset occurred. At the temperature of $60^{\circ} \mathrm{C}$, the maximum corrosion layer thickness appeared at $1 \mathrm{~cm}$. Compared with that at the temperature of $25^{\circ} \mathrm{C}$, the location of the corrosion layer with the maximum thickness was shifted to the liquid level. By comparing these two kinds of alloy, it can be concluded that the corrosion of $\mathrm{Pb}-\mathrm{Sb}$ alloy was concentrated at a range of $0-2 \mathrm{~cm}$. In the section of $0-2 \mathrm{~cm}$, the corrosion layers were thick (corrosion layer thickness $>100 \mu \mathrm{m}$ ). At $1 \mathrm{~cm}$, the corrosion layer thickness could reach $380 \mu \mathrm{m}$. However, the thickness of alloy corrosion layers are greatly decreased (corrosion layer thickness $<10 \mu \mathrm{m}$ ) from $1 \mathrm{~cm}$ to $2 \mathrm{~cm}$. The corrosive range of $\mathrm{Pb}-\mathrm{Sn}$ alloy was broader and the change of corrosion layer thickness was mild. The thickness of corrosion layer reached its maximum value at $1 \mathrm{~cm}, 142 \mu \mathrm{m}$, which was smaller than that of $\mathrm{Pb}-\mathrm{Sb}$ alloy.

After using scanning electron microscope to further observe the accelerated corrosion, the microstructures on the corrosion layer surfaces of the alloy electrodes corresponding to different heights are shown in Figure 7. The corrosion layer surface structure of the $\mathrm{Pb}-\mathrm{Sb}$ alloy was a loose porous structure at $0 \mathrm{~cm}$ and $1 \mathrm{~cm}$. However, it became compact at $2 \mathrm{~cm}$, which can suggest that the corrosion at $2 \mathrm{~cm}$ was much weakened. In comparison, the corrosion layer surface structure of the $\mathrm{Pb}-\mathrm{Sn}$ alloy shared the same structure in the range of $0-2 \mathrm{~cm}$ which presented the granular stack. By comparing the morphologies of the spots showing the most serious alloy corrosion (at $1 \mathrm{~cm})$, it can be seen that the corrosion layers of the $\mathrm{Pb}-\mathrm{Sb}$ alloy were looser in structure than that of the $\mathrm{Pb}-\mathrm{Sn}$ alloy, meaning solution had easier access to the inner corrosion layers and provided space for the acceleration of corrosion and the deformation of corrosion product.

\subsection{Possible functional mechanism of hydrogen evo- lution property applicable for corrosion}

From previous corrosion experiments, it can be concluded that the $\mathrm{Pb}-\mathrm{Sb}$ alloy and $\mathrm{Pb}-\mathrm{Sn}$ alloy share similar corrosion layer thickness and similar changing trend of corrosion layer surface appearance with height, but have distinct differences in the degree of corrosion. Therefore, we speculate that the corrosion mechanisms of the $\mathrm{Pb}-\mathrm{Sb}$ alloy and $\mathrm{Pb}-\mathrm{Sn}$ alloy are 


\section{MATEC Web of Conferences}

similar, and the degree of corrosion is related to the property of alloy.

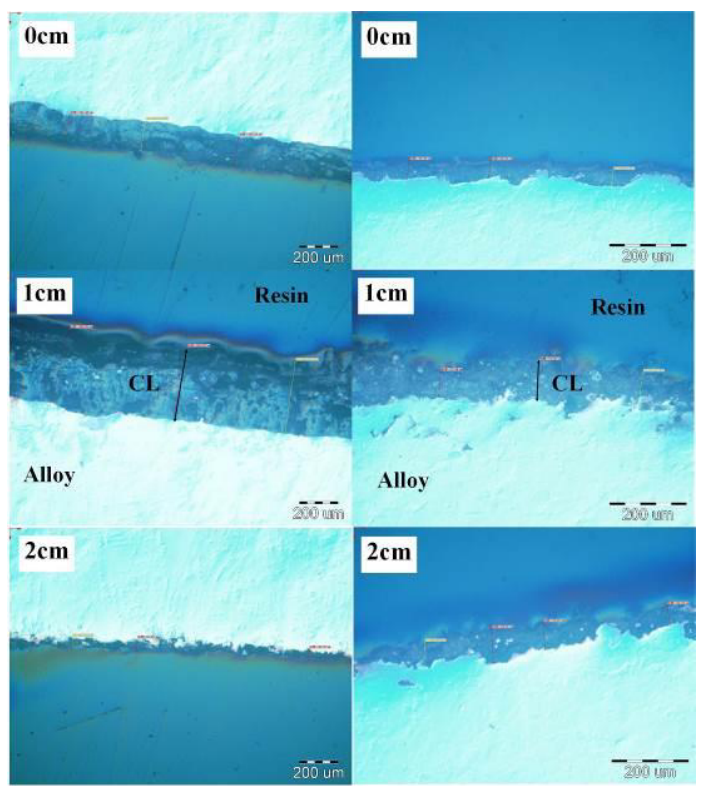

$\mathbf{P b}-\mathbf{S b}$

Pb-Sn

Figure 5. Cross-section metallographic microscope images of alloy at different heights $\left(60^{\circ} \mathrm{C}\right)$

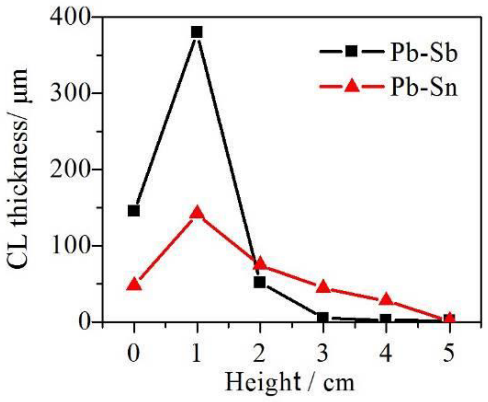

Figure 6. Changing curves of alloy corrosion layer thickness $\left(60^{\circ} \mathrm{c}\right)$

Because of the invasion property of sulfuric acid solution, a layer of liquid film was formed on the surface layer of negative strap. Nevertheless, under the influences of solution ion diffusion, the oxygen-recombination and the hydrogen evolution reaction during alloy floating charge, the $\mathrm{H}^{+}$ionic concentration and $\mathrm{SO}_{4}{ }^{2-}$ ionic concentration inside the liquid film are decreased with the increase of the distance away from the liquid level. According to certain researches ${ }^{[6]}$, the negative strap corrosion can be divided into three areas: (I) area under the cathodic protection, (II) lead sulfate corrosion area and (III) corrosion area in amorphous form, as shown in Figure 8.

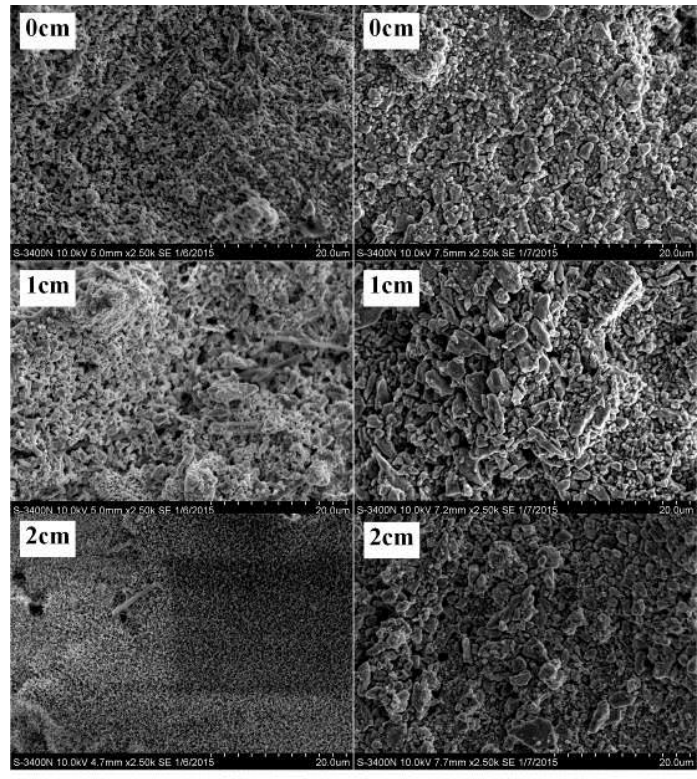

Pb-Sb

Pb-Sn

Figure 7. Surface scanning electron microscope images of alloy at different heights $\left(60^{\circ} \mathrm{C}\right)$

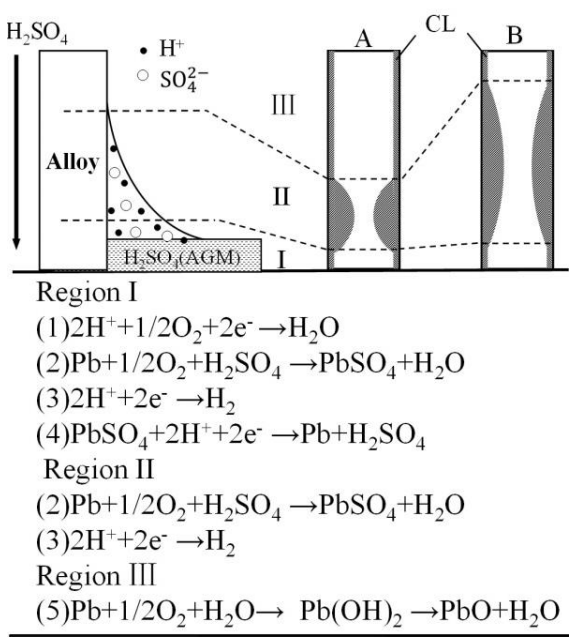

Figure 8 . Negative strap corrosion mechanism

From Figure 8, it can be seen that besides the change of electrode potential, the change of $\mathrm{H}^{+}$ionic concentration is also a key factor in affecting alloy corrosion during the process of changing from protected area (I) to area (II) with serious corrosion. As the solution layers on the lead alloy electrode surface are very thin, the diffusion of ions is under restrictions. When lead alloy has hydrogen evolution reaction here, the $\mathrm{H}^{+}$ions inside the liquid layers will 


\section{EMME 2015}

be consumed, and the $\mathrm{pH}$ value of the lead alloy surface will be influenced accordingly. It is thus clear that the hydrogen evolution rate of alloy has the possibility of influencing the location of the alloy corrosion layer with the maximum thickness. In the meantime, the rate of the alloy hydrogen evolution reaction may affect the thickness of the alloy corrosion layer. On one hand, the evolution of hydrogen can bring a loose structure to the corrosion layer. The $\mathrm{H}^{+}$ions and $\mathrm{SO}_{4}{ }^{2-}$ ions can smoothly enter the inner part of the corrosion layers, and thus can accelerate the crosswise corrosion rate of the alloy. On the other hand, hydrogen evolution reaction can decrease the $\mathrm{H}^{+}$ionic concentration on alloy surface and make the $\mathrm{pH}$ value on electrode surface higher. It can be seen from the electrode- $\mathrm{pH}$ phase diagram of $\mathrm{Pb}$ that higher $\mathrm{pH}$ value is more beneficial for the generation of $\mathrm{PbSO}_{4}$ and the acceleration of alloy corrosion. As a result, it can be speculated that the hydrogen evolution rate of alloy is the main factor affecting the layout of alloy corrosion layers.
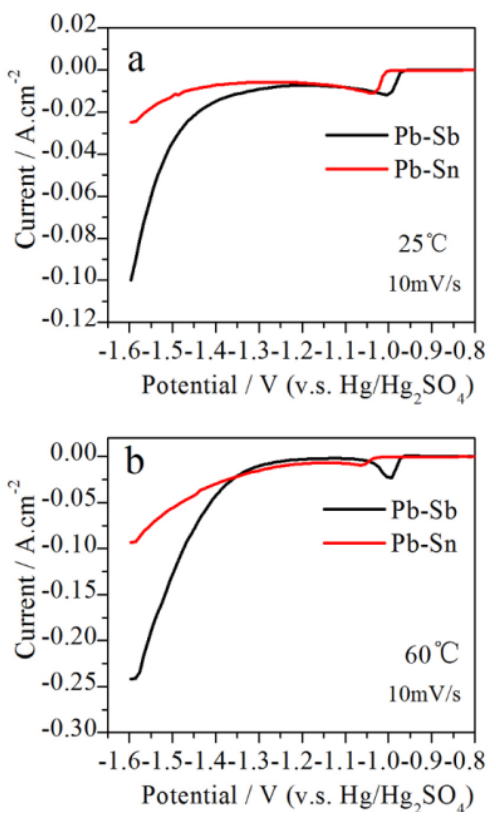

Figure 9. Linear sweep voltammetry of alloy electrode: a. $25^{\circ} \mathrm{c} ;$ b. $60^{\circ} \mathrm{c}$

In order to verify the speculation of this mechanism, linear sweep voltammetry tests were conducted to these two kinds of lead alloy electrode at temperatures of $25^{\circ} \mathrm{C}$ and $60^{\circ} \mathrm{C}$. See Figure 9 for the linear sweep voltammetry curves of the two alloy electrodes at temperatures of $25^{\circ} \mathrm{C}$ and $60^{\circ} \mathrm{C}$. As shown in Figure 9, when the voltage is below $-1.2 \mathrm{~V}$ (v.s. $\mathrm{Hg} / \mathrm{Hg}_{2} \mathrm{SO}_{4}$ electrode), the surface of lead alloy electrode will mainly have hydrogen evolution reaction and the current will be hydrogen evolution reaction current. At the same potentials, the hydrogen evolution reaction current on the surface of the $\mathrm{Pb}-\mathrm{Sb}$ alloy will be much bigger than that of the $\mathrm{Pb}-\mathrm{Sn}$ alloy which means the hydrogen evolution reaction rate of the $\mathrm{Pb}-\mathrm{Sb}$ alloy is higher than that of the $\mathrm{Pb}-\mathrm{Sn}$ alloy. The rise of temperature will reduce the activation energy of hydrogen evolution reaction, and thus will reduce the hydrogen evolution over-potential and improve the hydrogen evolution rate. By comparing Figure 9a and Figure 9b, it can be seen that the hydrogen evolution currently is great on the surface of alloy electrode at temperature of $60^{\circ} \mathrm{C}$. Alloy has higher hydrogen evolution reaction rate, meaning the hydrogen evolution rate of the $\mathrm{Pb}-\mathrm{Sb}$ alloy is higher than that of the $\mathrm{Pb}-\mathrm{Sn}$ alloy, whereas the hydrogen evolution rate of the $\mathrm{Pb}-\mathrm{Sb} / \mathrm{Pb}-\mathrm{Sn}$ alloy is higher at temperature of $60^{\circ} \mathrm{C}$ than $25^{\circ} \mathrm{C}$.

From the speculation, it can be concluded that with the same height, the higher hydrogen evolution rate on alloy surface will lead to less $\mathrm{H}^{+}$ionic concentration. It means that the corrosion area (II) appears in the alloy, meaning the distance between the corrosion area with the maximum thickness and the liquid level is shorter. The location where the maximum corrosion area thickness of the $\mathrm{Pb}-\mathrm{Sb}$ alloy can be found was lower than that of the $\mathrm{Pb}-\mathrm{Sn}$ alloy; the locations of the $\mathrm{Pb}-\mathrm{Sb} / \mathrm{Pb}-\mathrm{Sn}$ alloy corrosion areas with the maximum thickness formed at temperature of $60^{\circ} \mathrm{C}$ were lower than that at temperature of $25^{\circ} \mathrm{C}$. There is no difference between the results and the previous corrosion experiments. Higher hydrogen evolution rate can bring more evoluted hydrogen. The disturbance of hydrogen will lead alloy corrosion layers to form loose porous structures and thus can provide easier access for the $\mathrm{H}^{+}$ions and $\mathrm{SO}_{4}{ }^{2-}$ ions to enter the inner part of the corrosion layers. As a result, the degree of corrosion will be higher. The maximum corrosion layer thickness of the $\mathrm{Pb}-\mathrm{Sb}$ alloy is bigger than that of the $\mathrm{Pb}-\mathrm{Sn}$ alloy which is the same with previous experimental results.

The lead alloy cell structures of the Pb-Sb alloy and $\mathrm{Pb}-\mathrm{Sn}$ alloy are of different morphologies. With the same additive amount, the corrosion resistant performance of the $\mathrm{Pb}-\mathrm{Sb}$ alloy is weaker ${ }^{[9]}$. According to related documents ${ }^{[4]}$, the oxidation potentials of $\mathrm{Sb}$ and $\mathrm{Sn}$ in acidic condition are $-0.458 \mathrm{~V}$ and $-0.694 \mathrm{~V}$ respectively (v.s. $\mathrm{Hg} / \mathrm{Hg}_{2} \mathrm{SO}_{4}$ ). Both potentials are higher than the surface potential of negative strap ${ }^{[4,6]}$. The oxidation reaction of $\mathrm{Sb} / \mathrm{Sn}$ is slow, whereas the intergranular corrosion rate caused by $\mathrm{Sb} / \mathrm{Sn}$ segregation is low. Omae T et al. ${ }^{[8]}$ take $\mathrm{Pb}$-Sb alloy and pure $\mathrm{Pb}$ alloy as counter electrodes and observe the corrosion situation of the negative $\mathrm{Pb}-\mathrm{Ca}$ alloy. It has been found in the research that the corrosion of the $\mathrm{Pb}-\mathrm{Ca}$ alloy electrode was more serious when $\mathrm{Pb}-\mathrm{Sb}$ alloy was used as the counter electrode instead of pure $\mathrm{Pb}$ alloy. The authors think the reason for this phenomenon is that the $\mathrm{Sb}$ which was dissolved out from the counter electrode became negative through electrolyte reaction, and it was evoluted out from the negative surface. As a consequence, higher hydrogen evolution rate of alloy was generated and the corrosion was accelerated. The hydrogen evolution reaction rate on the surface of alloy plays a more important role in the 


\section{MATEC Web of Conferences}

influence of negative corrosion.

\section{CONCLUSION}

This paper selected $\mathrm{Pb}-\mathrm{Sb}$ alloy and $\mathrm{Pb}-\mathrm{Sn}$ alloy to study the negative strap corrosion-resistant characteristics of lead acid battery, and analyzed the mechanism of negative strap corrosion. Studies show that the hydrogen evolution reaction rate of alloy is the main factor that impacts the distribution of alloy corrosion layers. The hydrogen evolution reaction rate on alloy surface can affect the $\mathrm{H}^{+}$ionic concentration in alloy liquid films, and further leaves an influence on the location of the negative corrosion area with the maximum thickness and the corrosion layer thickness of the alloy. When the hydrogen evolution reaction rate of alloy is high, the distribution of alloy corrosion is shown as Figure 9a pattern: the corrosion area becomes narrow and small; the distance between the corrosion area with maximum thickness and the liquid level is short; the corrosion layer thickness is great, and thus the negative strap corrosion fracture risk becomes higher. When the hydrogen evolution reaction rate of alloy is low, the distribution of alloy corrosion is shown as Figure 9b pattern: The corrosion area becomes broad and big; the distance between the corrosion area with maximum thickness and the liquid level is long; the corrosion layer thickness is small, and thus the negative strap corrosion fracture risk becomes lower, making it more applicable for the negative strap alloy of lead acid battery.

\section{REFERENCES}

[1] Sawai, K. \& Tsuboi, Y. \& Osumi, S. 2008. Corrosion of $\mathrm{Pb}-\mathrm{Ca}-\mathrm{Sn}$ Alloy during Potential Step Cycles. J Power Sources. 175(1): 604-612.

[2] Yan, M.L. \& Zhao, W.Z. 2010. Influence of Temperature on Corrosion Behavior of PbCaSnCe Alloy in $4.5 \mathrm{M}$ H2SO4 Solution. J. Power Sources 195(2): 631-637.

[3] Zhang, W.Q. Li, A.J. \& Chen, H.Y. et al. 2012. The Effect of Rare earth Metals on the Microstructure and Electrochemical Corrosion Behavior of Lead Calcium Grid Alloys in Sulfuric Acid Solution. J Power Sources 203: 145-152.

[4] Ruetschi, P. 2004. Aging Mechanisms and Service Life of Lead-Acid Batteries. J Power Sources 127(1-2): 33-44.

[5] Wagner, R. 1995. Failure Modes of Valve-Regulated Lead/Acid Batteries in Different Applications. J Power Sources 53(1): 153-162.

[6] Pavlov, D. Dimitrov, M. \& Petkova, G. et al. 1995. The Effect of Selenium on the Electrochemical Behavior and Corrosion of Pb-Sn Alloys Used in Lead-Acid Batteries. J Electrochem Soc 142(9): 2919-2927.

[7] Hua, S.N. Guo, Y.L. \& Wang, Z.R. 1993. A Study of the Corrosion of Negative-Plate Lead-Antimony Lugs in Lead/Acid Batteries. J Power Sources 45(2): 131-137.

[8] Omae, T. Osumi, S. \& Takahashi, K. et al. 1997. Negative Corrosion of Lead-Antimony Alloys in Lead-Acid Batteries at High Temperatures. $J$ Power Sources 65(1-2): 65-70.

[9] Osorio, W.R. Peixoto, L.C. \& Garciag, A. 2010. Comparison of Electrochemical Performance of As-Cast $\mathrm{Pb}-1$ wt. \% $\mathrm{Sn}$ and $\mathrm{Pb}-1$ wt. \% $\mathrm{Sb}$ Alloys for Lead-Acid Battery Components. J Power Sources 195(6): 1726-1730. 